\title{
The relationship between body fat and respiratory function in young adults
}

\author{
Tim J.T. Sutherland ${ }^{1}$, Christene R. McLachlan², Malcolm R. Sears ${ }^{3}$, \\ Richie Poulton ${ }^{4}$ and Robert J. Hancox ${ }^{2}$
}

Affiliations: 'Dept of Respiratory Medicine, Leeds Teaching Hospitals, Leeds, UK. ${ }^{2}$ Dept of Preventive and
Social Medicine, Dunedin School of Medicine, University of Otago, Dunedin, New Zealand. ${ }^{3}$ Firestone Institute
for Respiratory Health, Michael de Groote School of Medicine, McMaster University and St Joseph's
Healthcare, Hamilton, Ontario, Canada. ${ }^{4}$ Dept of Psychology, University of Otago, Dunedin, New Zealand.

Correspondence: Robert J. Hancox, Dept of Preventive and Social Medicine, Dunedin School of Medicine, University of Otago, P0 Box 913, Dunedin 9054, New Zealand. E-mail: bob.hancoxQdotago.ac.nz

ABSTRACT The relationship between adiposity and respiratory function is poorly understood. Most studies investigating this have used indirect measures of body fat and few have assessed how changes in adiposity influence lung function.

Body fat measured by bio-electrical impedance analysis, body mass index, waist circumference, spirometry, body plethysmography and transfer factor were measured at ages 32 and 38 years in 361 nonsmoking, non-asthmatic participants from a population-based birth cohort.

Higher percentage body fat was associated with lower spirometric and plethysmographic lung volumes, but not with airflow obstruction, or transfer factor at 32 years. Changes in adiposity between ages 32 and 38 years were inversely associated with changes in lung volumes. These associations were generally stronger in men than women, but an association between increasing adiposity and lower airway function (forced expiratory volume in $1 \mathrm{~s} /$ forced vital capacity) was only found in women. Similar associations were found for body mass index and waist circumference.

Higher percentage body fat is associated with lower lung volumes. Direct and indirect measures of adiposity had similar associations with lung function. Adiposity had a greater effect on lung volumes in men than women but was associated with airway function only in women. There was little evidence that adiposity influenced transfer factor.

@ERSpublications

Increasing adiposity leads to airflow obstruction in women, but causes greater impairment of lung volumes in men http://ow.ly/idjK30210i8

Received: Dec 302015 | Accepted after revision: May 042016 | First published online: July 282016

Support statement: The Dunedin Multidisciplinary Health and Development Research Unit was funded by the Health Research Council of New Zealand. Duke University (USA) provided additional funding for respiratory data collection at 38 years. Funding information for this article has been deposited with the Open Funder Registry.

Conflict of interest: Disclosures can be found alongside the online version of this article at erj.ersjournals.com

Copyright OERS 2016 


\section{Introduction}

The mechanics of respiratory function are determined by an interaction of the lungs, the chest wall and respiratory muscles. Since John Hutchinson published his studies on the use of the spirometer [1], factors affecting the interpretation of respiratory function measurements have been of interest. Obesity is one factor that has been shown, in most studies, to be associated with lower static lung volumes but spirometric lung volumes and airflow are usually within normal limits except in massive obesity [2-4]. The relationship with transfer factor is less clear, with some reports of higher transfer factors and some with lower $[2,5-7]$.

A number of methods of estimating adiposity have been used to describe the relationship between obesity and respiratory function. As a measure of obesity, body mass index (BMI) has an inconsistent association with respiratory function, with some studies demonstrating a significant negative relationship [8-10] and others not $[11,12]$. If the effects of obesity on respiratory function are proportional to adiposity, these findings may reflect the fact that BMI is a poor measure of adiposity. Alternative measures, such as waist circumference and waist-to-hip ratio, have also been negatively associated with spirometric lung volumes in several population based studies [13-15], especially in men [11, 12]. Skin-fold thickness has also been used to estimate total body fat and has been negatively associated with some measures of respiratory function $[12,16,17]$.

Few studies have used direct measures of body fat to explore its association with respiratory function. Those using methods such as dual-energy X-ray absorptiometry (DXA) have tended to be in small, selected populations $[8,18-21]$. Bio-electrical impedance provides an alternative method of measuring body fat without the difficulties of operator dependence and is suitable for large population-based studies $[22,23]$. There are limited data using this technique but body fat measured in this way has been shown to be inversely associated with forced expiratory volume in $1 \mathrm{~s}$ (FEV1) and forced vital capacity (FVC) in elderly men [10]. To our knowledge, there have been no comprehensive studies using bio-electrical impedance to examine the association of adiposity with spirometry, lung volumes and transfer factor in the same population. Furthermore, there is also little published evidence on how changes in adiposity influence respiratory function. In one of the few published studies, CHEN et al. [24] demonstrated an inverse relationship between weight gain and spirometric measures in a cohort study over a range of ages. Studies investigating the effect of weight loss through obesity surgery have shown an increase in respiratory function $[25,26]$.

We explored the relationship between adiposity measured by bio-electrical impedance and a comprehensive range of respiratory function tests in a population based cohort of young adults aged 32 years. In addition, we used BMI and waist circumference as indirect measures of body fat to compare their associations with respiratory function. We further explored how changes in these measures of adiposity between years 32 and 38 were associated with changes in respiratory function. Because there is an established association between obesity and asthma in this cohort [27, 28], we excluded asthmatics from the analysis in order to examine the effect of adiposity on otherwise healthy lungs. For the same reasons, smokers of cigarettes and cannabis were also excluded.

\section{Methods}

\section{Study members}

The Dunedin Multidisciplinary Health and Development Study is a longitudinal investigation of health and behaviour in a population-based birth cohort [27-30]. Study members were born in Dunedin, New Zealand, between April 1972 and March 1973. 1037 children (91\% of eligible births, 52\% male) participated in the first follow-up at 3 years, which constituted the base sample for the remainder of the study. The cohort represented the full range of socioeconomic status in New Zealand's South Island and is mostly of New Zealand European ethnicity. 972 (96\%) of 1015 living study members participated in the assessment at 32 years and 961 study members participated at age 38 years. The study was approved by the Otago Ethics Committee (Dunedin, New Zealand). Written informed consent was obtained from each study member.

Study members who reported that they had asthma (a self-reported diagnosis of asthma) with compatible symptoms in the previous 12 months were excluded from the analysis (figure 1). Current smokers (those who had smoked in the last 12 months) were also excluded, as were those who had more than a 5 pack-year history of smoking, those who smoked cannabis in the past year or had a lifetime history of more than one "joint-year" (equivalent to smoking one cannabis cigarette a day for 1 year) [31]. Pregnant women were also excluded.

\section{Respiratory function measurements}

At both ages studied, a broad range of lung function tests including spirometry (FEV1 and FVC), total lung capacity (TLC), functional residual capacity (FRC), residual volume (RV), specific airway conductance 


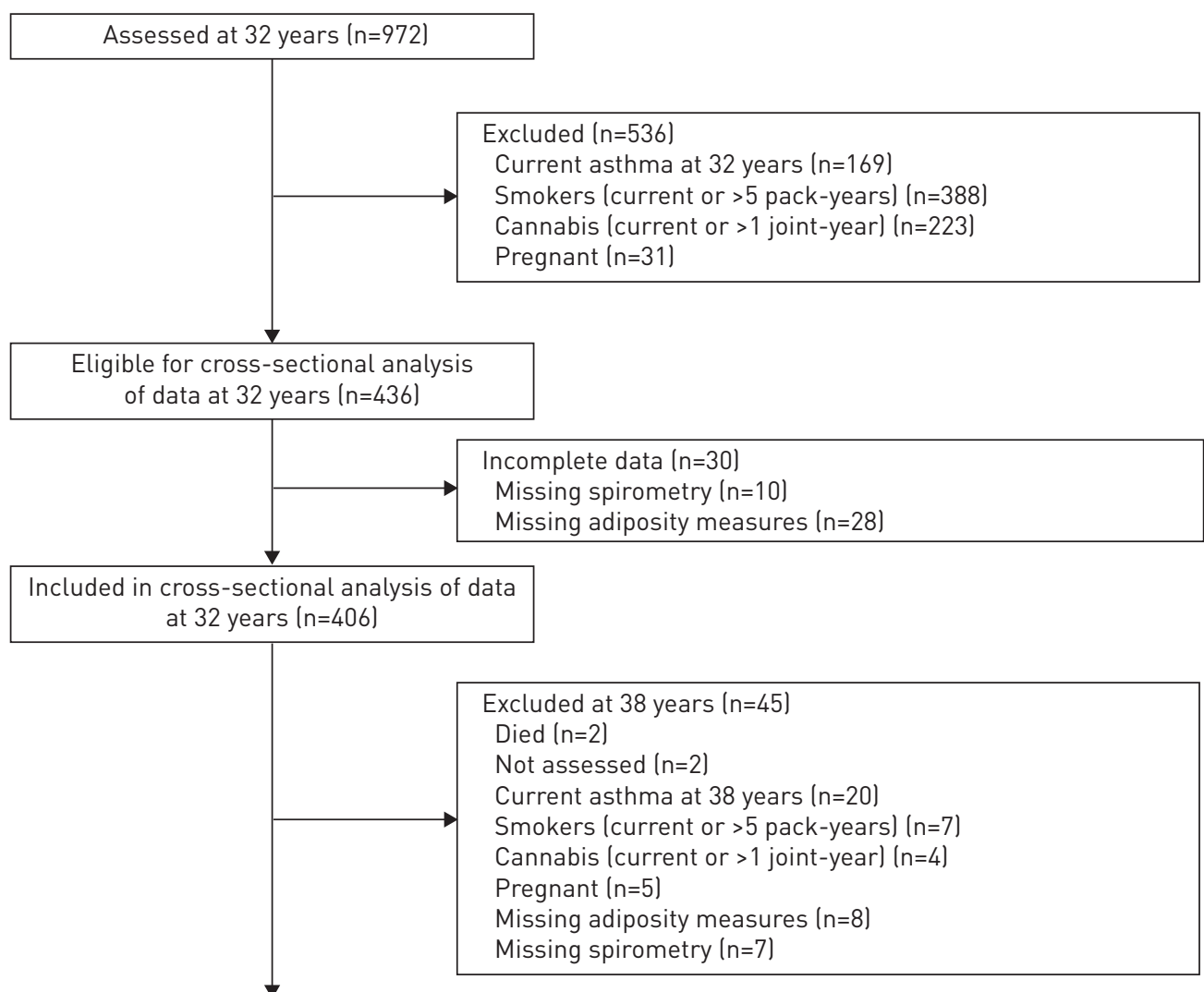

Included in longitudinal analysis $(n=361)$

FIGURE 1 Flow diagram of participant inclusion for the cross-sectional and longitudinal analyses.

adjusted for thoracic gas volume (sGaw), transfer factor for carbon monoxide (TLCO), and alveolar volume (VA) were measured using a body plethysmograph (CareFusion, Yorba Linda, CA, USA) [32-34]. This system uses a heated wire mass flow sensor and methane dilution for measurement of alveolar volume and calculation of TLCO. Portable spirometers (Spiropro at 32 years, SpiroUSB at age 38 years (both CareFusion)) were used to test study members who declined to sit in the plethysmograph or were unable to attend the research unit. Equipment was calibrated daily, and weekly quality control measures were obtained to ensure accuracy and precision of test equipment.

At each age, haemoglobin was measured using an automated haematology analyser (Sysmex Corporation, Kobe, Japan) and pre-test exhaled carbon monoxide was measured using a Micro CO monitor (CareFusion). The mean of two tests of exhaled carbon monoxide was recorded.

\section{Anthropometry and body fat measurements}

Anthropometric measurements were made in light clothing without shoes. Height was measured to the nearest millimetre and weight to the nearest $0.1 \mathrm{~kg}$. Body mass index (BMI) was calculated in $\mathrm{kg} \cdot \mathrm{m}^{-2}$. Waist measurements were made to the nearest millimetre at the narrowest level approximately half way between the costal border and the iliac crest. All body measures were done twice and the mean of the two values was used.

Body fat percentage was measured by means of bioelectrical impedance analysis using a Tanita BC-418MA (Tokyo, Japan) segmental body composition analyser. The Tanita uses a 50- $\mathrm{Hz}$ current source, with electrodes in each hand and beneath each foot, to measure impedance to electrical conductivity as it passes through body fluids and calculate total body fat as a percentage of total body mass and trunk fat mass in $\mathrm{kg}$.

\section{Statistical analysis}

Multiple linear regression was used to explore how each measure of respiratory function (dependent variable) related to percentage body fat, BMI, waist circumference and trunk fat mass, adjusting for height at 32 years. Transfer factor was also adjusted for haemoglobin and pre-test exhaled CO levels. Because the 
measures of adiposity are likely to be correlated, separate regression analyses were performed for each of these predictors. Initial analyses tested whether the influence of adiposity on lung function differed between men and women by testing for statistical interactions between sex and each measure of adiposity. Because many of these were statistically significant, subsequent analyses were conducted for men and women separately.

To assess the influence of change in adiposity on lung function, multiple linear regression analyses were repeated using each measure of respiratory function at 38 years as the dependent variable and the change in each adiposity measure between 32 and 38 years as the main predictor in separate analyses. These analyses also adjusted for the earlier measure of lung function at 32 years and height at 32 years. Initial analyses tested for interactions between sex and change in adiposity: because many of these were statistically significant, these analyses were also conducted for men and women separately.

To facilitate comparisons of effect size between different measures of adiposity and lung function, standardised regression $(\beta)$ co-efficients were calculated for both cross-sectional and longitudinal analyses. A $\beta$ co-efficient of 1 implies that a one standard deviation change in adiposity is associated with a one standard deviation change in respiratory function. We also report the longitudinal and cross-sectional associations with each unit measure of adiposity in standard deviation (z-scores) derived from the cohort.

Histograms of the residuals and scatter plots of residual versus fitted values were inspected to ensure that the distributions of the residuals were approximately normal and randomly scattered versus the fitted values. Log-transformation of the dependent lung function values improved the distribution of the residuals in some cases, but none of these transformations made a material difference to the regression analyses (data not shown). One outlier with an extremely low and probable erroneous FEV1 value was excluded from analyses of spirometry. Analyses were performed using Stata 13.1 (Stata Corporation, College Station, TX, USA).

\section{Results}

The total numbers of study members included in the cross-sectional analysis at 32 years and the follow-up analysis at age 38 , following exclusion of those with asthma, smokers, and those who were pregnant are shown in figure 1. The number of participants included in each analysis varies slightly because of missing data and these are provided in the tables. No study members were unable to perform plethysmography because of their body habitus, but two eligible participants refused to sit in the body plethysmograph at 32 years and three refused at 38 years. Mean adiposity and lung function measures at each age are shown in table 1. At 32 years,

TABLE 1 Measures of adiposity and respiratory function for non-smoking asymptomatic women and men

\begin{tabular}{|c|c|c|c|c|c|c|}
\hline & \multicolumn{3}{|c|}{ Women } & \multicolumn{3}{|c|}{ Men } \\
\hline & 32 years & 38 years & Change & 32 years & 38 years & Change \\
\hline Adiposity & & $n=188$ & & & $n=173$ & \\
\hline $\mathrm{BMI} \mathrm{kg} \cdot \mathrm{m}^{-2}$ & $25.8 \pm 5.6$ & $26.4 \pm 5.6$ & $0.6 \pm 2.8$ & $26.9 \pm 4.2$ & $27.6 \pm 4.3$ & $0.6 \pm 2.1$ \\
\hline Waist circumference $\mathrm{cm}$ & $79.5 \pm 11.5$ & $80.2 \pm 11.0$ & $0.7 \pm 6.6$ & $89.6 \pm 9.2$ & $90.7 \pm 10.0$ & $1.5 \pm 5.6$ \\
\hline Trunk fat mass $\mathrm{kg}$ & $13.0 \pm 6.5$ & $13.5 \pm 6.3$ & $0.5 \pm 3.2$ & $11.5 \pm 4.4$ & $12.6 \pm 4.4$ & $1.0 \pm 2.5$ \\
\hline $\mathrm{FEV}_{1} \mathrm{~L}$ & $3.41 \pm 0.42$ & $3.19 \pm 0.40$ & $-0.21 \pm 0.18$ & $4.56 \pm 0.58$ & $4.28 \pm 0.56$ & $-0.28 \pm 0.25$ \\
\hline FVC L & $4.21 \pm 0.54$ & $4.07 \pm 0.52$ & $-0.15 \pm 0.22$ & $5.77 \pm 0.70$ & $5.53 \pm 0.71$ & $-0.24 \pm 0.29$ \\
\hline $\mathrm{FEV}_{1} / \mathrm{FVC} \%$ & $81.0 \pm 5.1$ & $78.7 \pm 5.2$ & $-2.3 \pm 3.0$ & $79.1 \pm 5.3$ & $77.6 \pm 5.5$ & $-1.5 \pm 2.7$ \\
\hline Plethysmography & & $n=184$ & & & $n=169-170$ & \\
\hline TLC L & $5.56 \pm 0.65$ & $5.64 \pm 0.71$ & $0.09 \pm 0.26$ & $7.39 \pm 0.88$ & $7.45 \pm 0.94$ & $0.07 \pm 0.36$ \\
\hline FRC L & $2.79 \pm 0.56$ & $2.57 \pm 0.57$ & $-0.23 \pm 0.40$ & $3.36 \pm 0.74$ & $3.10 \pm 0.72$ & $-0.26 \pm 0.56$ \\
\hline
\end{tabular}

Data are presented as mean \pm SD, unless otherwise stated. Current smokers of cigarettes or cannabis, ex-smokers with history of 5 pack-years or 1 joint-year or greater, current asthmatics, and pregnant women were all excluded. Study members with missing values for lung function at either age were also excluded. Gas transfer values are adjusted for haemoglobin [32]. Differences in the numbers for each lung function measure are due to differences in the number completing the respiratory function tests and providing haemoglobin samples. BMI: body mass index; FEV1: forced expiratory volume in $1 \mathrm{~s}$; FVC: forced vital capacity; TLC: total lung capacity; FRC: functional residual capacity; RV: residual volume; TLCo: transfer factor of the lung for carbon monoxide; VA: alveolar volume. 
$18 \%$ of eligible participants were obese $\left(\mathrm{BMI} \geqslant 30 \mathrm{~kg} \cdot \mathrm{m}^{-2}\right)$ and a further $39 \%$ were overweight $\left(\mathrm{BMI} \geqslant 25 \mathrm{~kg} \cdot \mathrm{m}^{-2}\right)$. At 38 years, $21 \%$ were obese and $40 \%$ were overweight. At each age, the distributions of $\mathrm{BMI}$, waist circumference and trunk fat were skewed to the right. The changes in adiposity measures from 32 to 38 years were normally distributed. In both sexes, the change in weight between ages 32 and 38 years was inversely correlated with the weight at 32 years (women $\mathrm{r}=-0.13$, $\mathrm{p}=0.0067$; men $\mathrm{r}=-0.18, \mathrm{p}=0.0001$ ).

\section{Cross-sectional associations}

Percentage body fat, BMI, waist circumference, and trunk fat mass were all inversely associated with spirometric and static lung volumes (table 2). Most of these associations were statistically significant except those between waist circumference and $\mathrm{FEV}_{1}$ in either sex, waist circumference and lung volumes in women, BMI and FVC in either sex, and BMI and FEV1 in men. There were numerous statistically significant sex-by-adiposity interactions for static lung volumes. In general, the coefficients were greater in men, although there was no consistent sex difference in the effect sizes ( $\beta$ co-efficients), and all associations were in the same direction for both sexes.

There was no evidence of cross-sectional associations between adiposity and FEV1/FVC ratios. There were also no significant associations between adiposity and airway conductance (sGaw) (data not shown). There was also little evidence of an association between adiposity and gas transfer. Body fat and BMI were associated with higher values for transfer factor when adjusted for alveolar volume (TLCO/VA) in women, but this was accounted for by the reduction in alveolar volume rather than an increase in gas transfer per se. Cross-sectional associations at 38 years showed a similar pattern of findings (data not shown).

\section{Longitudinal associations}

Changes in all measures of adiposity were significantly inversely associated with spirometric and static lung volumes, with the exception of residual volume, for which the inverse associations were not significant in women and the inverse association with a change in waist circumference was not statistically significant in men (table 3). There were several statistically significant sex-by-adiposity interactions and the associations between the change in adiposity and lung function were generally stronger in men than women.

There was an inverse association between change in adiposity and the FEV1/FVC ratio in women but not men. There was no association with airway conductance in either sex. Transfer factor was inversely associated with adiposity measures, but not when this was adjusted for alveolar volume.

Scatterplots of the association between change in percentage body fat and change in lung function are shown in figures 2, 3 and 4 . There is little evidence of non-linear or " $U$-shaped" associations.

\section{Discussion}

This study of non-smoking non-asthmatic young adults found that adiposity is associated with lower lung function across a broad range of dynamic and static lung volumes. These associations were observed in cross-sectional analyses at 32 years and a consistent pattern of associations between changes in adiposity and lung function was found at follow-up 6 years later. The associations were similar for different measures of adiposity. These findings support a causal inference and indicate that increasing adiposity leads to a restrictive pattern of lung function impairment. In addition, increases in adiposity between 32 and 38 years were associated with a decline in FEV1/FVC ratios in women, indicating that adiposity also adversely affects airway function in women. Adiposity had no effect on gas transfer: although increasing adiposity was associated with lower transfer factors in the longitudinal analysis, this was accounted for by the reduction in the volume of alveolar gas distribution rather than impairment in gas transfer per se.

With the emerging obesity epidemic, there is a greater need to understand the effect of adiposity on respiratory function. This is the only study to date to comprehensively explore the association between percentage body fat measured by bio-electrical impedance and other measures of adiposity with a wide range of standard respiratory function tests. In general, the strength of the association between percent body fat, BMI, waist circumference and trunk fat mass with most measures of respiratory function was similar. Perhaps this is not surprising given that these measures of adiposity were strongly correlated (for women, $r>0.88$; for men, $r>0.79$ ). However, it has been suggested that inconsistencies in previous reports of the effects of obesity on spirometric volumes [8-12] may be because measurements such as BMI do not distinguish between adiposity and muscularity, which may have opposing effects $[8,10,12,16,35]$. Our finding that percentage body fat and BMI had similar effect sizes to waist circumference and trunk fat mass suggest that the distribution of body fat does not have a major influence on the effects on lung function, at least for the young adult age group included in this study. 
TABLE 2 Associations between adiposity and lung function at 32 years

\begin{tabular}{|c|c|c|c|c|c|c|c|c|c|}
\hline & \multicolumn{4}{|c|}{ Women } & \multicolumn{4}{|c|}{ Men } & \multirow{2}{*}{$\begin{array}{c}\text { Interaction } \\
\mathrm{p} \text {-value }\end{array}$} \\
\hline & $\begin{array}{l}\text { Coefficient } \\
\text { (95\% CI) }\end{array}$ & $\begin{array}{c}\text { z-score } \\
\text { coefficient }\end{array}$ & $\begin{array}{c}\text { Standardised } \boldsymbol{\beta} \\
\text { coefficient }\end{array}$ & p-value & $\begin{array}{l}\text { Coefficient } \\
(95 \% \mathrm{CI})\end{array}$ & $\begin{array}{l}\text { z-score } \\
\text { coefficient }\end{array}$ & $\begin{array}{c}\text { Standardised } \beta \\
\text { coefficient }\end{array}$ & p-value & \\
\hline Spirometry & \multicolumn{3}{|c|}{$\mathrm{n}=212$} & \multicolumn{5}{|c|}{$n=194$} & \\
\hline \multicolumn{10}{|l|}{$\mathrm{FEV} 1 \mathrm{~mL}$} \\
\hline Body fat & $-9(-15--2)$ & -0.021 & -0.159 & 0.007 & $-14(-27--2)$ & -0.025 & -0.137 & 0.028 & 0.304 \\
\hline BMI & $-9(-18-0)$ & -0.021 & -0.119 & 0.045 & $-14(-32-3)$ & -0.024 & -0.099 & 0.112 & 0.373 \\
\hline Waist & $-4(-8-0)$ & -0.009 & -0.100 & 0.092 & $-8(-16-0)$ & -0.013 & -0.118 & 0.052 & 0.332 \\
\hline Trunk fat & $-10(-18--3)$ & -0.024 & -0.158 & 0.009 & $-18(-34--2)$ & -0.030 & -0.130 & 0.032 & 0.448 \\
\hline \multicolumn{10}{|l|}{$\mathrm{FVC} \mathrm{mL}$} \\
\hline Body fat & $-9(-17--1)$ & -0.017 & -0.134 & 0.021 & $-20(-35--5)$ & -0.028 & -0.156 & 0.008 & 0.115 \\
\hline BMI & $-9(-20-2)$ & -0.017 & -0.097 & 0.095 & $-17(-37-4)$ & -0.023 & -0.095 & 0.111 & 0.290 \\
\hline Waist & $-3(-9-3)$ & -0.006 & -0.069 & 0.237 & $-10(-19-0)$ & -0.013 & -0.119 & 0.040 & 0.207 \\
\hline Trunk fat & $-11(-21--2)$ & -0.021 & -0.137 & 0.022 & $-25(-44--6)$ & -0.035 & -0.149 & 0.009 & 0.234 \\
\hline \multicolumn{10}{|l|}{$\mathrm{FEV}_{1} / \mathrm{FVC} \%$} \\
\hline Body fat & $-0.03(-0.12-0.06)$ & -0.006 & -0.044 & 0.522 & $0.02(-0.13-0.16)$ & 0.003 & 0.016 & 0.817 & 0.584 \\
\hline $\mathrm{BMI}$ & $-0.04(-0.16-0.09)$ & -0.007 & -0.038 & 0.579 & $-0.02(-0.22-0.17)$ & -0.004 & -0.018 & 0.813 & 0.917 \\
\hline Waist & $-0.03(-0.09-0.03)$ & -0.005 & -0.060 & 0.387 & $-0.01(-0.10-0.08)$ & -0.001 & 0.012 & 0.864 & 0.717 \\
\hline Trunk fat & $-0.03(-0.14-0.08)$ & -0.006 & -0.037 & 0.608 & $0.02(-0.16-0.21)$ & 0.004 & 0.018 & 0.799 & 0.627 \\
\hline Plethysmography & & $\mathrm{n}=204$ & & & & $n=188-189$ & & & \\
\hline \multicolumn{10}{|l|}{$\mathrm{TLC} \mathrm{mL}$} \\
\hline Body fat & $-19(-28--10)$ & -0.029 & -0.224 & $<0.001$ & $-39(-57--21)$ & -0.044 & -0.241 & $<0.001$ & 0.024 \\
\hline BMI & $-22(-35--9)$ & -0.034 & -0.189 & 0.001 & $-44(-69--19)$ & -0.049 & -0.199 & 0.001 & 0.047 \\
\hline Waist & $-11(-17--4)$ & -0.017 & -0.187 & 0.001 & $-22(-33--11)$ & -0.025 & -0.219 & $<0.001$ & 0.069 \\
\hline Trunk fat & $-23-(-34--12)$ & -0.036 & -0.230 & $<0.001$ & $-50(-73--27)$ & -0.056 & -0.236 & $<0.001$ & 0.043 \\
\hline \multicolumn{10}{|l|}{$\mathrm{FRC} \mathrm{mL}$} \\
\hline Body fat & $-41(-48--33)$ & -0.073 & -0.560 & $<0.001$ & $-71(-85--56)$ & -0.096 & -0.530 & $<0.001$ & $<0.001$ \\
\hline $\mathrm{BMI}$ & $-58(-68--48)$ & -0.104 & -0.578 & $<0.001$ & $-109(-127--91)$ & -0.148 & -0.603 & $<0.001$ & $<0.001$ \\
\hline Waist & $-29(-34--25)$ & -0.053 & -0.597 & $<0.001$ & $-51(-59--44)$ & -0.070 & -0.619 & $<0.001$ & $<0.001$ \\
\hline Trunk fat & $-51(-60--43)$ & -0.092 & -0.596 & $<0.001$ & $-98(-115--80)$ & -0.132 & -0.560 & $<0.001$ & $<0.001$ \\
\hline \multicolumn{10}{|l|}{$\mathrm{RV} \mathrm{mL}$} \\
\hline Body fat & $-11(-16--6)$ & -0.037 & -0.286 & $<0.001$ & $-22(-31--13)$ & -0.060 & -0.330 & $<0.001$ & 0.019 \\
\hline $\mathrm{BMI}$ & $-15(-21--8)$ & -0.049 & -0.273 & $<0.001$ & $-31(-43--20)$ & -0.085 & -0.346 & $<0.001$ & 0.006 \\
\hline Waist & $-8(-12--5)$ & -0.028 & -0.314 & $<0.001$ & $-14(-20--10)$ & -0.040 & -0.354 & $<0.001$ & 0.035 \\
\hline Trunk fat & $-14(-20--8)$ & -0.046 & -0.296 & $<0.001$ & $-29(-40--19)$ & -0.080 & -0.338 & $<0.001$ & 0.012 \\
\hline
\end{tabular}


TABLE 2 Continued

\begin{tabular}{|c|c|c|c|c|c|c|c|c|c|}
\hline & \multicolumn{4}{|c|}{ Women } & \multicolumn{4}{|c|}{ Men } & \multirow{2}{*}{$\begin{array}{c}\text { Interaction } \\
\text { p-value }\end{array}$} \\
\hline & $\begin{array}{l}\text { Coefficient } \\
(95 \% \mathrm{CI})\end{array}$ & $\begin{array}{l}\text { z-score } \\
\text { coefficient }\end{array}$ & $\begin{array}{l}\text { Standardised } \beta \\
\text { coefficient }\end{array}$ & p-value & $\begin{array}{l}\text { Coefficient } \\
(95 \% \mathrm{CI})\end{array}$ & $\begin{array}{l}\text { z-score } \\
\text { coefficient }\end{array}$ & $\begin{array}{l}\text { Standardised } \beta \\
\text { coefficient }\end{array}$ & p-value & \\
\hline$T \mathrm{LCO} \mathrm{mmoL} \cdot \mathrm{I}$ & & & & & & & & & \\
\hline Body fat & $-0.011(-0.029-0.008)$ & -0.009 & -0.066 & 0.262 & $-0.037(-0.078-0.004)$ & -0.021 & -0.117 & 0.077 & 0.218 \\
\hline BMI & $-0.012(-0.038-0.014)$ & -0.010 & -0.055 & 0.351 & $-0.008(-0.065-0.049)$ & -0.005 & -0.019 & 0.784 & 0.950 \\
\hline Waist & $-0.009(-0.022-0.004)$ & -0.008 & -0.082 & 0.159 & $-0.020(-0.045-0.005)$ & -0.012 & -0.103 & 0.119 & 0.435 \\
\hline Trunk fat & $-0.015(-0.038-0.008)$ & -0.013 & -0.078 & 0.194 & $-0.039(-0.091-0.014)$ & -0.022 & -0.095 & 0.145 & 0.391 \\
\hline \multicolumn{10}{|c|}{$T$ LCO/VA mmoL $\cdot \mathrm{min}^{-1} \cdot \mathrm{kPa}^{-1} \cdot \mathrm{L}^{-1}$} \\
\hline BMI & $0.005(0.000-0.010)$ & 0.025 & 0.138 & 0.042 & $0.005(-0.003-0.014)$ & 0.022 & 0.090 & 0.234 & 0.682 \\
\hline Waist & $0.002(-0.000-0.004)$ & 0.010 & 0.108 & 0.113 & $0.001(-0.003-0.005)$ & 0.003 & 0.023 & 0.750 & 0.578 \\
\hline Trunk fat & $0.005(0.000-0.009)$ & 0.023 & 0.149 & 0.034 & $0.002(-0.007-0.010)$ & 0.006 & 0.026 & 0.719 & 0.352 \\
\hline
\end{tabular}

Multiple linear regression of each measure of lung function using body fat percentage, body mass index (BMI), waist circumference and trunk fat mass as the independent variables in separate analyses, adjusted for height. Analyses of transfer factor of the lung for carbon monoxide (TLCO) and TLco/alveolar volume (VA) are also adjusted for haemoglobin and exhaled carbon monoxide measures. Results are displayed as coefficients with $95 \%$ confidence intervals, z-score (standard deviation) coefficients, and standardised regression ( $\beta$ ) coefficients. p-values $<0.05$ are highlighted in bold. Coefficients represent the difference in spirometry, lung volume, airway conductance, or gas transfer for each unit of difference in adiposity. Z-score coefficients represent the standard deviation change in lung function measure associated with each unit of difference in the measure of adiposity. The units of adiposity are: \% of body weight for body fat, $\mathrm{kg} \cdot \mathrm{m}^{-2}$ for BMl, $\mathrm{cm}$ for waist circumference and $\mathrm{kg}$ for trunk fat. The standardised regression ( $\beta$ ) coefficients are the standard deviation change in lung function measure associated with each standard deviation difference in the measure of adiposity. Interaction p-values are from tests for interaction between sex and adiposity measures. Current smokers of cigarettes or cannabis, ex-smokers with history of 5 pack-years or 1 joint-year or greater, current asthmatics and pregnant women were all excluded. The number in each analysis varies due to differences in the number completing the respiratory function tests. FEV1: forced expiratory volume in $1 \mathrm{~s}$; FVC: forced vital capacity; TLC: total lung capacity; FRC: functional residual capacity; RV: residual volume. 
TABLE 3 Association between change in adiposity and change in lung function between 32 and 38 years

\begin{tabular}{|c|c|c|c|c|c|c|c|c|c|}
\hline & \multicolumn{4}{|c|}{ Women } & \multicolumn{4}{|c|}{ Men } & \multirow{2}{*}{$\begin{array}{c}\text { Interaction } \\
\mathrm{p} \text {-value }\end{array}$} \\
\hline & Coefficient $(95 \% \mathrm{Cl})$ & $\begin{array}{c}\text { z-score } \\
\text { coefficient }\end{array}$ & $\begin{array}{c}\text { Standardised } \beta \\
\text { coefficient }\end{array}$ & p-value & Coefficient $(95 \% \mathrm{Cl})$ & $\begin{array}{l}\text { z-score } \\
\text { coefficient }\end{array}$ & $\begin{array}{c}\text { Standardised } \beta \\
\text { coefficient }\end{array}$ & p-value & \\
\hline Spirometry & & $\mathrm{n}=187$ & & & & $n=173$ & & & \\
\hline \multicolumn{10}{|l|}{$\mathrm{FEV} 1 \mathrm{~mL}$} \\
\hline Body fat & $-14(-21--8)$ & -0.036 & -0.141 & $<0.001$ & $-27(-38--17)$ & -0.049 & -0.157 & $<0.001$ & 0.036 \\
\hline BMI & $-24(-33--16)$ & -0.060 & -0.166 & $<0.001$ & $-44(-60--28)$ & -0.078 & -0.165 & $<0.001$ & 0.025 \\
\hline Waist & $-8(-11--4)$ & -0.019 & -0.126 & $<0.001$ & $-18(-24--12)$ & -0.032 & -0.177 & $<0.001$ & 0.005 \\
\hline Trunk fat & $-20(-27--12)$ & 0.049 & -0.155 & $<0.001$ & $-37(-50--23)$ & -0.066 & -0.166 & $<0.001$ & 0.026 \\
\hline \multicolumn{10}{|l|}{ FVC mL } \\
\hline Body fat & $-9(-17--2)$ & -0.018 & -0.071 & 0.018 & $-30(-42-17)$ & -0.042 & -0.135 & $<0.001$ & 0.009 \\
\hline BMI & $-20(-31--10)$ & -0.039 & -0.108 & $<0.001$ & $-52(-71--33)$ & -0.074 & -0.156 & $<0.001$ & 0.003 \\
\hline Waist & $-5(-10--0)$ & -0.010 & -0.063 & 0.037 & $-20(-27--13)$ & -0.028 & -0.156 & $<0.001$ & 0.001 \\
\hline Trunk fat & $-14(-24--5)$ & -0.027 & -0.086 & $<0.004$ & $-44(-60--28)$ & -0.062 & -0.157 & $<0.001$ & 0.002 \\
\hline \multicolumn{10}{|l|}{ FEV $1 / F V C \%$} \\
\hline Body fat & $-0.17(-0.27-0.06)$ & -0.032 & -0.124 & 0.002 & $-0.08(-0.20-0.04)$ & -0.014 & -0.047 & 0.201 & 0.326 \\
\hline $\mathrm{BMI}$ & $-0.18(-0.33--0.03)$ & -0.034 & -0.094 & 0.020 & $-0.07(-0.25-0.12)$ & -0.012 & -0.026 & 0.484 & 0.404 \\
\hline Waist & $-0.08(-0.15--0.02)$ & -0.016 & -0.105 & 0.009 & $-0.05(-0.12-0.02)$ & -0.009 & -0.051 & 0.162 & 0.527 \\
\hline Trunk fat & $-0.19(-0.32--0.06)$ & -0.037 & -0.117 & 0.004 & $-0.05(-0.21-0.11)$ & -0.009 & -0.023 & 0.538 & 0.210 \\
\hline Plethysmography & & $\mathrm{n}=184$ & & & & $n=169-170$ & & & \\
\hline \multicolumn{10}{|l|}{ TLC mL } \\
\hline Body fat & $-16(-26--7)$ & -0.023 & -0.090 & 0.001 & $-50(-65--35)$ & -0.053 & -0.172 & $<0.001$ & $<0.001$ \\
\hline BMI & $-28(-41--15)$ & -0.039 & -0.109 & $<0.001$ & $-72(-95--49)$ & -0.077 & -0.163 & $<0.001$ & 0.001 \\
\hline Waist & $-10(-16--5)$ & -0.014 & -0.095 & $<0.001$ & $-26(-34--16)$ & -0.027 & -0.154 & $<0.001$ & 0.004 \\
\hline Trunk fat & $-22(-34--11)$ & -0.031 & -0.100 & $<0.001$ & $-62(-82--43)$ & -0.067 & -0.168 & $<0.001$ & $<0.001$ \\
\hline \multicolumn{10}{|l|}{$\mathrm{FRC} \mathrm{mL}$} \\
\hline Body fat & $-49(-61--37)$ & -0.086 & -0.334 & $<0.001$ & $-93(-113--74)$ & -0.129 & -0.423 & $<0.001$ & $<0.001$ \\
\hline BMI & $-79(-95--63)$ & -0.138 & -0.382 & $<0.001$ & $-161(-188--133)$ & -0.223 & -0.476 & $<0.001$ & $<0.001$ \\
\hline Waist & $-32(-39--24)$ & -0.055 & -0.364 & $<0.001$ & $-56(-67--45)$ & -0.078 & -0.442 & $<0.001$ & $<0.001$ \\
\hline Trunk fat & $-66(-81-52)$ & -0.116 & -0.370 & $<0.001$ & $-131(-155--107)$ & -0.182 & -0.462 & $<0.001$ & $<0.001$ \\
\hline \multicolumn{10}{|l|}{$\mathrm{RV} \mathrm{mL}$} \\
\hline Body fat & $-8(-17-2)$ & -0.021 & -0.082 & 0.115 & $-14(-28-0)$ & -0.036 & -0.115 & 0.047 & 0.377 \\
\hline BMI & $-12(-26-1)$ & -0.033 & -0.091 & 0.079 & $-23(-45--2)$ & -0.059 & -0.123 & 0.033 & 0.396 \\
\hline Waist & $-4(-10-2)$ & -0.011 & -0.075 & 0.148 & $-6(-15-2)$ & -0.016 & -0.091 & 0.117 & 0.607 \\
\hline Trunk fat & $-10(-22-2)$ & -0.028 & -0.089 & 0.088 & $-19(-37--1)$ & -0.049 & -0.122 & 0.036 & 0.342 \\
\hline
\end{tabular}




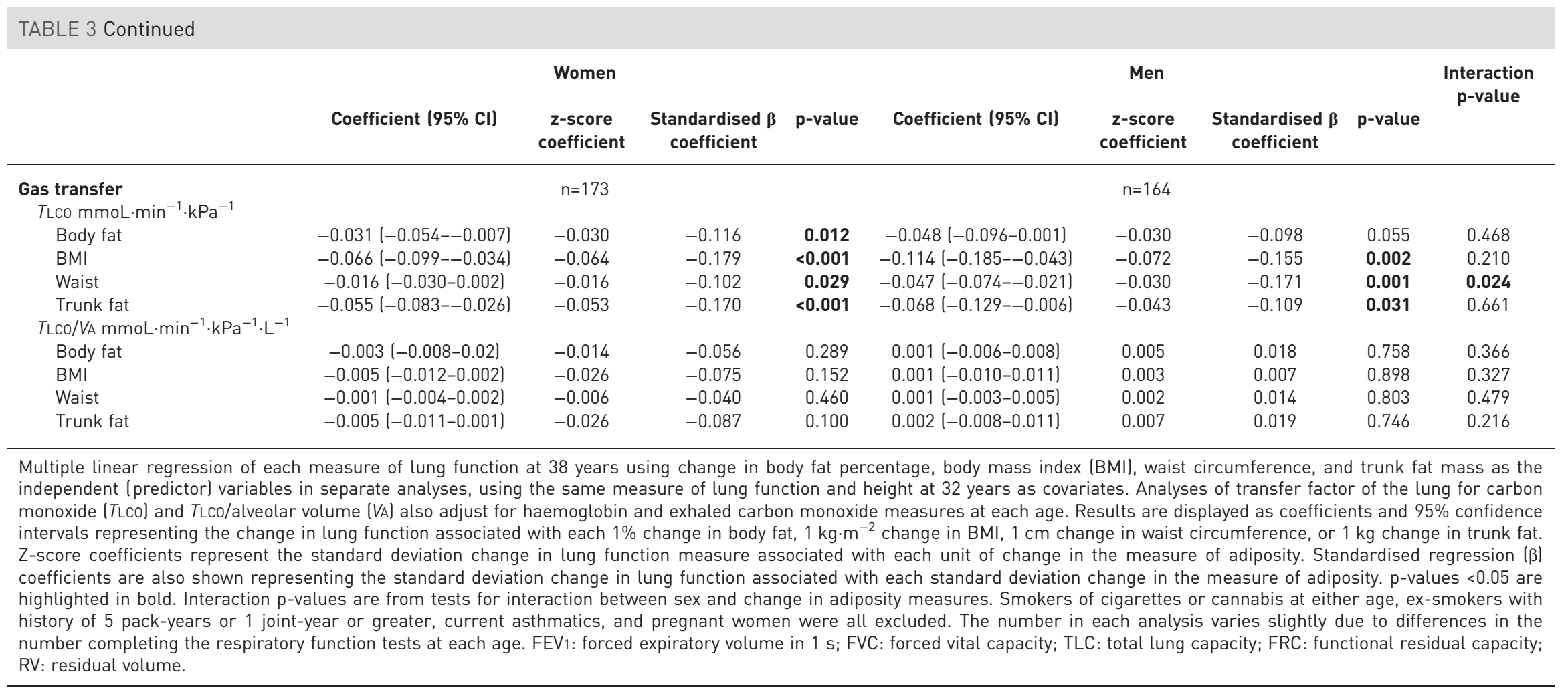



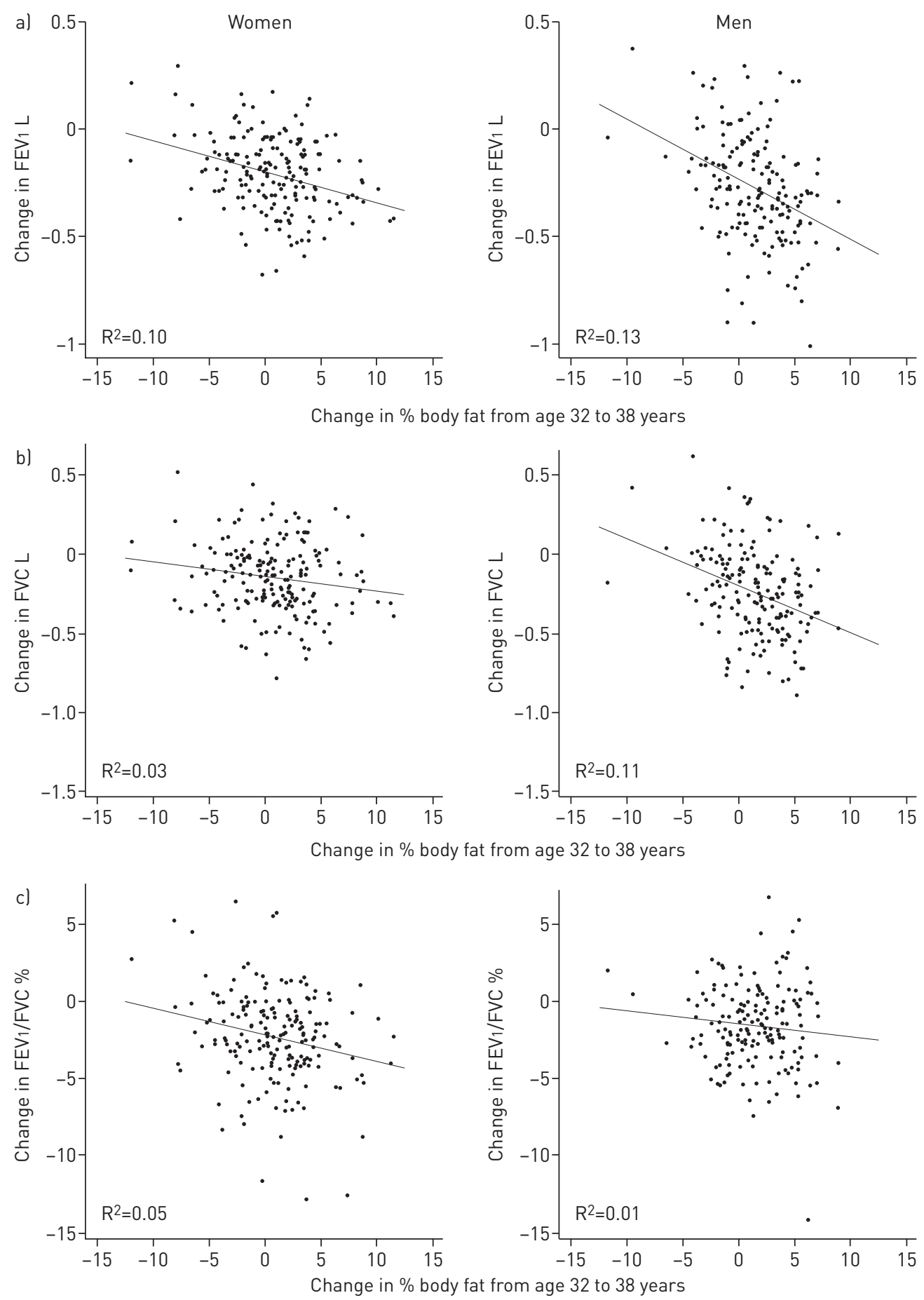

FIGURE 2 Scatter plots of change in spirometry against change in body fat percentage between ages 32 and 38 years for women and men with fitted linear regression lines. Changes in al forced expiratory volume in $1 \mathrm{~s}$ (FEV1), b) forced vital capacity (FVC) and c) FEV1/FVC.

The findings confirm that increasing adiposity is associated with reduced lung volumes [5]. This is likely to be due to the reduced compliance of the lungs caused by increased fat surrounding the chest wall and around the abdomen [17, 36, 37]. The reduction in FRC with increasing adiposity was proportionately greater than the reduction in TLC and RV and, as a consequence, there were also significant reductions in expiratory reserve volumes and increases in inspiratory capacities in both sexes (not shown). Although the direction of the associations was the same in both sexes, the effect sizes were generally stronger in men. This would suggest that, even in young men, the effect of central adiposity on lung volumes is important and the sex differences may reflect differences in the distribution of body fat in men and women. 

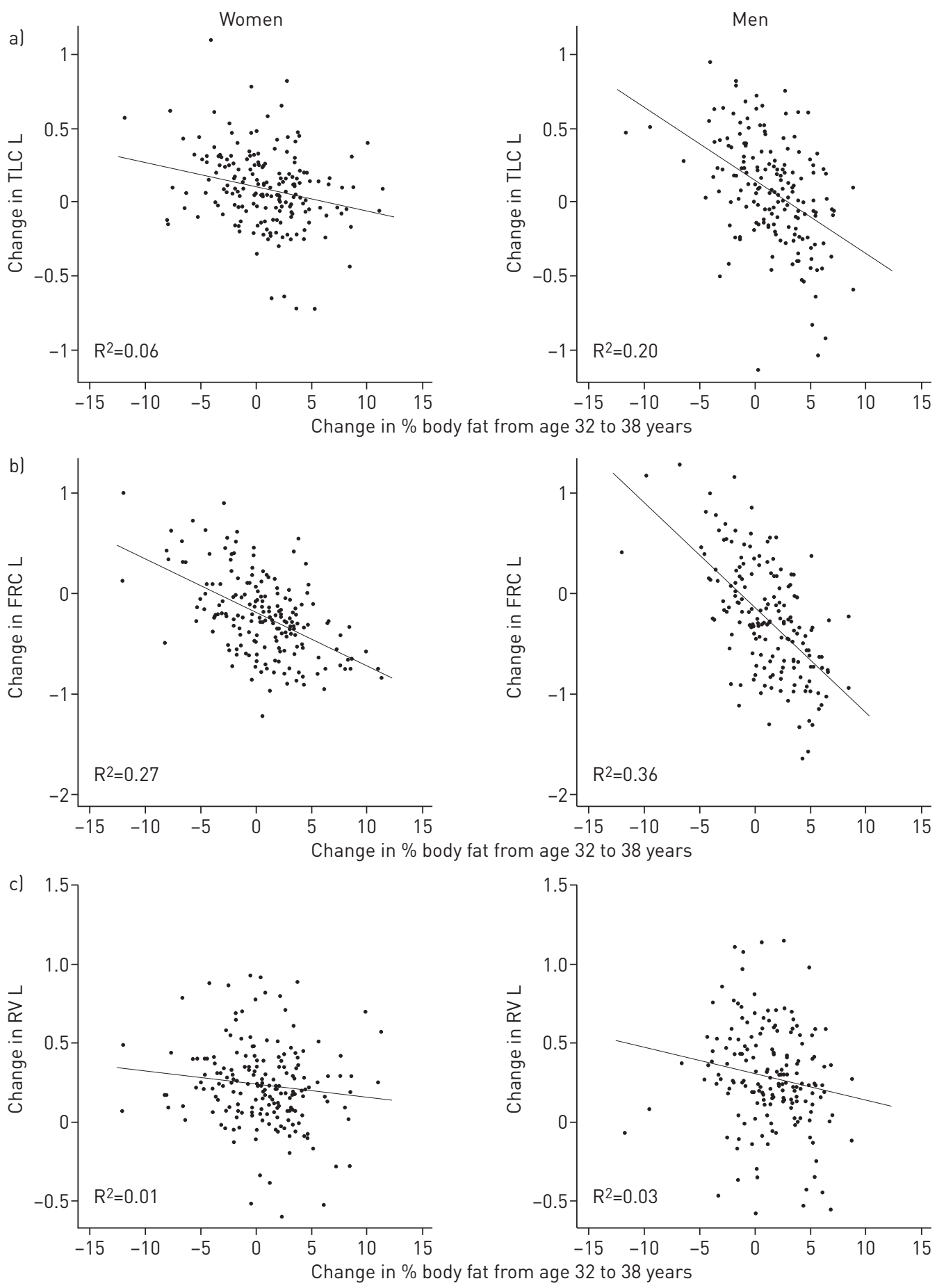

FIGURE 3 Scatter plots of change in plethysmographic lung volumes against change in body fat percentage between ages 32 and 38 years for women and men with fitted linear regression lines. Change in a) total lung capacity (TLC), b) functional residual capacity (FRC) and c) residual volume (RV).

An interesting finding of this study is the association between increases in adiposity and a decline in the FEV1/FVC ratio in women, which was not observed in men, indicating a possible differential effect of adiposity on airway function between the sexes. This may also reflect the established association between obesity and asthma in women, given that the risk of developing asthma in later life appears to be stronger in women, and that this association is weaker, or not present, in men [38]. We excluded participants with a self-reported diagnosis of asthma from this analysis and therefore the association between increasing adiposity and airflow obstruction was unlikely to be due to pre-existing asthma. This observation lends support to the hypothesis that one of the mechanisms for the association between obesity and asthma may 

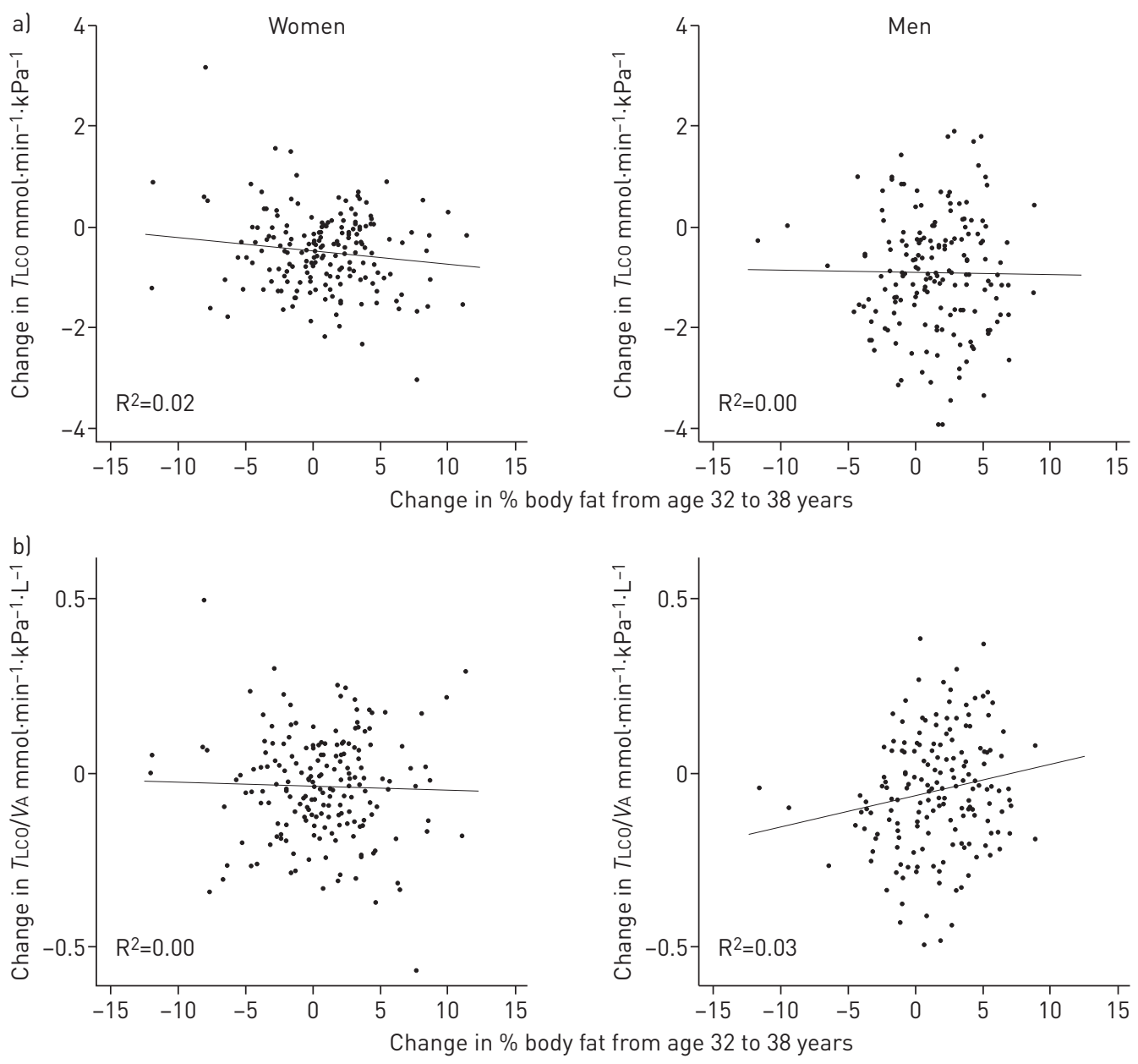

FIGURE 4 Scatter plots of change in gas transfer against change in body fat percentage between ages 32 and 38 years for women and men with fitted linear regression lines. Change in al transfer factor of the lung for carbon monoxide (TLCO) and b) TLCo/alveolar volume (VA).

be a mechanical effect of adiposity on airway function [38]. We did not, however, find any significant cross-sectional or longitudinal associations between adiposity and airway conductance (sGaw) in either men or women (not shown).

The present study has a number of strengths. To our knowledge, it is the first study of the association between percentage body fat measured by bio-electrical impedance and a broad range of respiratory function measurements in a large population-based study of young healthy adults and the first to compare percentage body fat with other measures of adiposity. We also believe that it is the first study of the effect of naturally occurring changes in adiposity on a broad range of lung function in a large population-based sample. Although bio-electrical impedance analysis may not be as accurate as DXA scanning, the real differences in fat measurement between these techniques are small and, for large epidemiological studies, it is regarded as a simple and valid measure of determining body composition [22, 23]. Indeed, from local data collected using the same bio-electrical impedance analyser and DXA scanning, close correlations for the measurement of body fat between the two were found ( $\mathrm{r}=0.95$ for women and $\mathrm{r}=0.88$ for men, $\mathrm{p}<0.001$; unpublished data). Limitations of this study include the fact that we have only studied young adults. Although the fact that all participants were the same age avoids confounding of the study findings by age, it also means that the findings may not be generalisable to children or older adults. Another limitation is that although the bio-electrical impedance analyser estimated trunk fat mass, it is unable to distinguish between abdominal and thoracic fat. Hence, we are unable to determine whether the distribution of central body fat influences lung function.

\section{Conclusion}

We have found that increased adiposity is associated with impairment in lung function across a broad range of static and dynamic lung volumes. These associations do not appear to depend on how adiposity is measured or whether body fat is centrally or peripherally distributed. We also observed that an increase 
in adiposity over time was associated with a worsening of airway function measured by the FEV1/FVC ratio in women.

\section{Acknowledgements}

We are grateful to the study members and their friends and families for their continued support. We thank the respiratory physiologists who obtained the measurements: Sue Filsell, Kirk Jurgens, Amanda Wallace, and Avis Williamson. Andrew Gray (all University of Otago, Dunedin, New Zealand) provided advice on the analyses. We also thank Phil A Silva, the study founder, and Terrie Moffitt and Avshalom Caspi (both Duke University, Durham, NC, USA) for their support.

Author contributions: T.J.T. Sutherland, C.R. McLachlan and R.J. Hancox conceived the study. M.R. Sears, R.J. Hancox, C.R. McLachlan, and R. Poulton collected the data. T.J.T. Sutherland and R.J. Hancox analysed the data and wrote the manuscript. C.R. McLachlan helped to prepare an earlier draft but did not live to see the final version. All other authors provided critical review of the manuscript and approved its submission

\section{References}

1 Hutchinson J. On the capacity of the lungs, and on the respiratory functions, with a view to establishing a precise and easy method for detecting disease by the spirometer. Med Chir Trans 1846; 29: 137-252.

Parameswaran K, Todd DC, Soth M. Altered respiratory physiology in obesity. Can Respir J 2006; 13: 203-210.

Littleton SW. Impact of obesity on respiratory function. Respirology 2012; 17: 43-49.

Salome CM, King GG, Berend N. Physiology of obesity and effects on lung function. J Appl Physiol 2010; 108: 206-211.

5 Ray CS, Sue DY, Bray G, et al. Effects of obesity on respiratory function. Am Rev Respir Dis 1983; 128: 501-506.

6 Enache I, Oswald-Mammosser M, Scarfone S, et al. Impact of altered alveolar volume on the diffusing capacity of the lung for carbon monoxide in obesity. Respiration 2011; 81: 217-222.

7 Oppenheimer BW, Berger KI, Rennert DA, et al. Effect of circulatory congestion on the components of pulmonary diffusing capacity in morbid obesity. Obesity 2006; 14: 1172-1180.

8 Santana H, Zoico E, Turcato E, et al. Relation between body composition, fat distribution, and lung function in elderly men. Am J Clin Nutr 2001; 73: 827-831.

9 Lazarus R, Sparrow D, Weiss ST. Effects of obesity and fat distribution on ventilatory function: the normative aging study. Chest 1997; 111: 891-898.

10 Wannamethee SG, Shaper AG, Whincup PH. Body fat distribution, body composition, and respiratory function in elderly men. Am J Clin Nutr 2005; 82: 996-1003.

11 Harik-Khan RI, Wise RA, Fleg JL. The effect of gender on the relationship between body fat distribution and lung function. J Clin Epidemiol 2001; 54: 399-406.

12 Lazarus R, Gore CJ, Booth M, et al. Effects of body composition and fat distribution on ventilatory function in adults. Am J Clin Nutr 1998; 68: 35-41.

13 Canoy D, Luben R, Welch A, et al. Abdominal obesity and respiratory function in men and women in the EPIC-Norfolk Study, United Kingdom. Am J Epidemiol 2004; 159: 1140-1149.

14 Chen R, Tunstall-Pedoe H, Bolton-Smith C, et al. Association of dietary antioxidants and waist circumference with pulmonary function and airway obstruction. Am J Epidemiol 2001; 153: 157-163.

15 Chen Y, Rennie D, Cormier YF, et al. Waist circumference is associated with pulmonary function in normal-weight, overweight, and obese subjects. Am J Clin Nutr 2007; 85: 35-39.

16 Cotes JE, Chinn DJ, Reed JW. Body mass, fat percentage, and fat free mass as reference variables for lung function: effects on terms for age and sex. Thorax 2001; 56: 839-844.

17 Collins LC, Hoberty PD, Walker JF, et al. The effect of body fat distribution on pulmonary function tests. Chest 1995; 107: 1298-1302.

18 De Lorenzo A, Petrone-De Luca P, Sasso GF, et al. Effects of weight loss on body composition and pulmonary function. Respiration 1999; 66: 407-412.

19 Li AM, Chan D, Wong E, et al. The effects of obesity on pulmonary function. Arch Dis Child 2003; 88: 361-363.

20 Sutherland TJT, Goulding A, Grant AM, et al. The effect of adiposity measured by dual-energy x-ray absorptiometry on respiratory function. Eur Respir J 2008; 32: 85-91.

21 Mafort TT, Madeira E, Madeira M, et al. Intragastric balloon for the treatment of obesity: evaluation of pulmonary function over a 3-month period. Lung 2012; 190: 671-676.

22 Roubenoff R. Applications of bioelectrical impedance analysis for body composition to epidemiologic studies. Am J Clin Nutr 1996; 64: 459S-462S.

23 Wattanapenpaiboon N, Lukito W, Strauss BJ, et al. Agreement of skinfold measurement and bioelectrical impedance analysis (BIA) methods with dual energy X-ray absorptiometry (DEXA) in estimating total body fat in Anglo-Celtic Australians. Int J Obes Relat Metab Disorders 1998; 22: 854-860.

24 Chen Y, Horne SL, Dosman JA. Body weight and weight gain related to pulmonary function decline in adults: a six year follow up study. Thorax 1993; 48: 375-380.

25 Hewitt S, Humerfelt S, Søvik TT, et al. Long-term improvements in pulmonary function 5 years after bariatric surgery. Obes Surg 2014; 24: 705-711.

26 de Souza SA, Faintuch J, Cecconello I. Spirometric function improves in the morbidly obese after 1-year post-surgery. Obes Surg 2010; 20: 1273-1277.

27 Hancox RJ, Milne BJ, Poulton R, et al. Sex differences in the relation between body mass index and asthma and atopy in a birth cohort. Am J Respir Crit Care Med 2005; 171: 440-445.

28 McLachlan CR, Poulton R, Car G, et al. Adiposity, asthma, and airway inflammation. J Allergy Clin Immunol 2007; 119: 634-639.

29 Sears MR, Greene JM, Willan AR, et al. A longitudinal, population-based, cohort study of childhood asthma followed to adulthood. $N$ Engl J Med 2003; 349: 1414-1422.

30 Poulton R, Moffitt TE, Silva PA. The Dunedin Multidisciplinary Health and Development Study: overview of the first 40 years, with an eye to the future. Soc Psychiatry Psychiatr Epidemiol 2015; 50: 679-693. 
31 Hancox RJ, Poulton R, Ely M, et al. Effects of cannabis on lung function: a population-based cohort study. Eur Respir J 2010; 35: 42-47.

32 Macintyre N, Crapo RO, Viegi G, et al. Standardisation of the single-breath determination of carbon monoxide uptake in the lung. Eur Respir J 2005; 26: 720-735.

33 Miller MR, Hankinson J, Brusasco V, et al. Standardisation of spirometry. Eur Respir J 2005; 26: 319-338.

34 Wanger J, Clausen JL, Coates A, et al. Standardisation of the measurement of lung volumes. Eur Respir J 2005; 26: 511-522.

35 Koziel S, Ulijaszek SJ, Szklarska A, et al. The effects of fatness and fat distribution on respiratory functions. Ann Hum Biol 2007; 34: 123-131.

36 Sharp JT, Barrocas M, Chokroverty S. The cardiorespiratory effects of obesity. Clin Chest Med 1980; 1: 103-118.

37 Zerah F, Harf A, Perlemuter L, et al. Effects of obesity on respiratory resistance. Chest 1993; 103: 1470-1476.

38 Rasmussen F, Hancox RJ. Mechanisms of obesity in asthma. Curr Opin Allergy Clin Immunol 2014; 14: 35-43. 